\title{
La alternativa cristiana en la modernidad tardía. Razones de la migración religiosa del catolicismo al pentecostalismo ${ }^{1}$
}

\author{
The Christian Alternative in Late Modernity. Reasons of Religious \\ Migration from Catholicism towards Pentecostalism
}
A alternativa cristã na modernidade tardia. Razões da migração religiosa do catolicismo ao pentecostalismo
Jean Paul Sarrazin² Paulina Arango ${ }^{3}$

\section{Resumen}

Este artículo aporta elementos para comprender las razones por las cuales un conjunto de personas adultas decide migrar de la Iglesia católica a una Iglesia pentecostal. Esta migración es vivida por el individuo como la expresión de su libertad personal y como una emancipación de la tradición de sus ancestros. A través del método etnográfico se estudiaron los cultos y el contexto extraeclesiástico en el que interactúan los sujetos, lo cual permitió observar que en la Iglesia pentecostal las personas reciben reconocimiento social, orientación cognitiva y moral, fuertes estímulos emocionales e inserción en lógicas de progreso modernas. En estos procesos se evidencia una tensión entre individualización y colectivización o entre libertad individual y sometimiento a una comunidad, dialéctica irresuelta que además es propia de la modernidad.

\section{Palabras clave}

pentecostalismo; religión; modernidad; individualización; emocionalidad

Abstract

This article provides elements to understand the reasons why a group of adults decide to migrate from the Catholic Church to a Pentecostal Church. The individuals experience this migration as an expression of their personal freedom and as emancipation from their ancestors' tradition. Using the ethnographic approach, we studied the cults and the context outside the church in which the subjects interact; this allowed us to observe that in the Pentecostal Church, people receive social recognition, cognitive and moral orientation, strong emotional stimulus, and insertion in the modern logic of progress. In these processes a tension is evident between individualization and colectivization, or between individual freedom and submission to a community, an unresolved dialectic which is also a main feature of modernity.

Keywords

Pentecostalism; religion; modernity; individualization; emotion

Resumo

Este artigo fornece elementos para compreender as razões pelas quais um grupo de pessoas adultas decide migrar da Igreja católica para uma Igreja pentecostal. Essa migração é vivida pelo indivíduo como a expressão de sua liberdade pessoal e como uma emancipação da tradição de seus ancestrais. Através do método etnográfico, foram estudados os cultos e o contexto extraeclesiástico no qual interatuam os sujeitos. Isso permitiu enxergar que na Igreja pentecostal as pessoas recebem reconhecimento social, orientação cognitiva e moral, fortes estímulos emocionais e inserção em lógicas de progresso modernas. Nesses processos, é evidente uma tensão entre individualização e coletivização ou entre liberdade individual e submissão a uma comunidade, dialética não resolvida que, adicionalmente, é característica da modernidade.

Palavras chave

pentecostalismo; religião; modernidade; individualização; emocionalidade

Artículo recibido el 24 de abril del 2016 y aprobado el 21 de diciembre del 2016

1 Este artículo procede de investigaciones realizadas por sus autores en el 2013 y el 2014 con financiación privada y por fuera de un proyecto institucional. Parte de los datos surgieron del trabajo de grado como requisito para obtener el título de Antropóloga por parte de Paulina Arango, bajo la dirección de Jean Paul Sarrazin.

2 Universidad de Antioquia, Medellín, Colombia. Correo electrónico: jean.sarrazin@udea.edu.co

3 Universidad de los Andes, Bogotá, Colombia. Correo electrónico: p.arango28@uniandes.edu.co 


\section{Introducción}

En Colombia y en América Latina, a medida que avanza el proceso de modernización, las iglesias católicas se vacían (Bastian, 2004; Beltrán, 2013a; Porcentaje de católicos, 2014; Parker, 2005). Esto no significa una disminución de la religiosidad, sino una transformación de esta: "las alternativas al catolicismo no han provenido del crecimiento de la no creencia y mucho menos del ateísmo" (Parker, 2005, p. 36). Dentro de las transformaciones del campo religioso se ha constatado una fuerte pluralización e hibridación de las expresiones religiosas (Bidegain y Demera, 2005; Tejeiro, Sanabria y Beltrán, 2007), promovida por factores como el debilitamiento del monopolio católico en el país (Beltrán, 2013a), la laicidad, la entrada en vigencia de una Constitución Política pluralista que garantiza la libertad de cultos y de consciencia (artículos 18 y 19), o un régimen liberal que promueve la apertura no solo económica y política, sino también cultural y, por ende, religiosa.

Con el fin de comprender las razones por las cuales los sujetos se sienten motivados a abandonar la Iglesia católica y adherirse a nuevos movimientos religiosos, se realizó una investigación que da origen al presente artículo, tomando como población de estudio un conjunto de personas que, al haber sido católicas en el pasado, ahora asisten regularmente a la Iglesia pentecostal llamada "Manantial de Vida Eterna".

Es importante considerar en este contexto de cambios que la libertad de creencia se une a la libertad de expresión (Bidegain, 2005, p. 21), y el derecho a la elección individual (de pareja, de casa, de carrera y también de religión) se convierte progresivamente en un imperativo incuestionable entre la población. Así, las iglesias evangélicas - particularmente las pentecostales - son elegidas por un número creciente de personas, quienes asisten, no por pertenencia familiar, sino por motivaciones personales. En efecto, en general los sujetos migran del catolicismo al pentecostalismo por decisión individual, lo cual hace que vayan muchas veces en contravía de sus tradiciones familiares. Este fenómeno local, como veremos, se inscribe en un proceso mucho más amplio de modernización y, más específicamente, de individualización, el cual ha sido teorizado en importantes obras (Bauman, 2000; Beck, 2009; Beck, Giddens y Lash, 2001; Elias, 1990; Giddens, 1997). Los conceptos analíticos provistos allí constituyen un marco que guía la tesis planteada en este artículo.

A propósito del crecimiento de las iglesias evangélicas en todo el mundo - especialmente en América Latina y África-, una serie de estudios ha mostrado que la mayoría de sus adeptos está en condiciones de marginalidad (Folquer y Amenta, 2010; Martin, 2002). En la misma línea, Beltrán (2013b, p. 70) nota que en Colombia los sectores sociales vulnerables, excluidos, desarraigados y los estratos socioeconómicos más bajos acuden a este tipo de iglesias como una "estrategia para hacer frente al desarraigo y la exclusión”. Aunque reconocemos el valor de ese tipo de estudios, es importante aclarar que este artículo no busca ahondar en aquellos factores socioeconómicos e históricos relacionados con la multiplicación de las iglesias evangélicas en general. Nuestro foco de estudio empírico, en cambio, ha sido a nivel micro, centrándonos en los sujetos mismos, sus experiencias vividas, los sentidos que otorgan a sus acciones, sus argumentaciones y sus medios de socialización inmediatos. Estas subjetividades son analizadas en el marco de las tendencias culturales que se han difundido en aquel proceso de modernización mencionado en el párrafo anterior.

La Iglesia Manantial de Vida Eterna (o Iglesia Manantial) pertenece a las "Asambleas de Dios", un conjunto de organizaciones eclesiales presente en varios países y consideradas cristianas protestantes, evangélicas y pentecostales. Aunque un buen número de las iglesias evangélicas son de origen norteamericano, con el paso del tiempo las actuales denominaciones locales han sido fundadas y son dirigidas por colombianos, de manera que sus prácticas se han "latinoamericanizado" (Bastian 2007), hibridándose con el catolicismo popular y alejándose considerablemente del protestantismo histórico (Beltrán, 2007). Conservan, eso sí, algunos rasgos del protestantismo, como el hecho de que no adoran a la Virgen ni a los santos católicos, y son independientes del Vaticano y de toda la institucionalidad 
e infraestructura católicas. Según Beltrán (2013b, p. 78 ), este tipo de iglesias constituyen "el movimiento más eficiente en términos de satisfacer las demandas religiosas de los colombianos", lo cual se relaciona con su gran flexibilidad y capacidad de adaptación frente a las realidades contemporáneas de los grupos sociales a los cuales se dirigen (Beltrán, 2013b, p. 61). Queda entonces la pregunta sobre cuáles son aquellas "demandas religiosas de los colombianos" y por qué estas no encuentran satisfacción en las iglesias católicas. A fin de contestar estas preguntas, hemos indagado sobre el sentido que tiene para las personas el "volverse cristianos" (según su propio lenguaje $)^{4}$.

\section{Metodología}

Según los objetivos de esta investigación, el método de estudio empírico más idóneo fue el etnográfico, lo cual permitió observaciones participantes directas en los cultos y otras actividades organizadas por la iglesia (como encuentros, discipulados, cursos, etc., explicados más adelante). Se siguió además un acercamiento fenomenológico (Berger y Luckmann, 2003), con el fin de comprender mejor las experiencias subjetivas vividas por los creyentes. Este estudio indaga también en el contexto extraeclesiástico en el que viven los sujetos. Así, hemos conocido diversas situaciones de la vida cotidiana de los asistentes a la Iglesia Manantial en sus casas, sus lugares de trabajo, sus medios familiares, etc. Con estas personas se realizaron entrevistas abiertas y con una leve estructuración progresiva (Guber, 2001), y se profundizó además en algunos aspectos de sus historias de vida.

Esta investigación empírica comienza con la asistencia a los cultos de la sede principal de la Iglesia Manantial, ubicada en la localidad de Fontibón (principalmente de estrato socioeconómico 2 y 3 ), al occidente de Bogotá. Este lugar de culto puede albergar unas 7.000 personas, pero la organización de la Iglesia Manantial cuenta con muchos más

4 El apelativo de "cristiano", que usaremos en adelante, es la manera en que se autodenominan los adeptos a las iglesias evangélicas 0 iglesias cristianas. miembros, ya que tiene otras sedes en la ciudad y en el país, lo cual suma en total 18 lugares de culto. De manera complementaria a las observaciones realizadas en la sede de Fontibón, se visitó una sede un poco más pequeña en la localidad de Suba, al norte de la ciudad, específicamente en el barrio Rionegro (de estrato socioeconómico 4).

Se asistió tanto a 28 cultos de esta Iglesia en diferentes horarios y días, como a tres grupos familiares. La asistencia a estas reuniones nos permitió contactar a diferentes sujetos para luego realizar entrevistas en profundidad con 26 mujeres y 12 hombres 5 , cuyas edades oscilan entre 28 y 70 años. A las personas entrevistadas, se les abordó con preguntas iniciales como: ¿ hace cuánto viene a la iglesia?, ¿ cómo llegó a ella?, ¿cómo se siente al venir a la iglesia? A partir de este tipo de frases iniciadoras, o a partir de diálogos que surgieron espontáneamente en diferentes circunstancias (en sus casas, en el transporte público o en cafeterías), se plantearon otras preguntas con el fin de profundizar en los argumentos de los sujetos y conocer diferentes aspectos de sus vidas, como sus actividades laborales, sus relaciones familiares y afectivas, o sus vivencias del pasado.

Por otro lado, y en complemento a lo anterior, se accedió a diferentes mensajes mediáticos que los mismos sujetos consumen, como es el caso del sitio en Internet de la Iglesia Manantial, algunas emisoras cristianas (como Cadena Radial Vida) o canales de televisión cristiana (como Enlace), cuyo lenguaje fue también objeto de análisis.

\section{La llegada a la Iglesia cristiana: una alternativa individualizada}

Entre la población estudiada hay una proporción considerable de madres cabezas de familia quienes han atravesado situaciones difíciles, como la infidelidad de su marido, una crisis económica, un divorcio, un intento de suicidio, la drogadicción o el alcoholismo de un hijo, una enfermedad grave o la pérdida de un familiar. A grandes rasgos, ellas aseguran que

5 Esta diferencia numérica entre los dos géneros corresponde con el hecho de que, en general, la mayoría de personas que se encuentra en los cultos cristianos son mujeres. 
la llegada a Manantial les ha traído cambios radicales y muy positivos: sus vidas cambiaron, tienen "paz espiritual" y son "otra persona”. Además, celebran el hecho de sentirse ahora mucho más cerca de Dios, el conocerlo realmente y hablar diariamente con él "como si fuera un amigo".

Para los cristianos - como para un buen número de colombianos hoy en día-, la palabra "religión" tiene connotaciones negativas, por lo que dicen "huirle a las religiones". Insisten en que lo de ellos no es una religión, sino una relación directa con Dios, una amistad y una comunión. Precisan que "religión" es el catolicismo, es decir, una institución hecha por los hombres, donde se comete el "error" de confesarse ante un cura, quien es "solo un hombre más". Dentro de sus creencias, la confesión se debe hacer directamente con Dios y sin intermediarios ${ }^{6}$. Sostienen además que en la Iglesia cristiana no hay una jerarquía, sino una "escalera ministerial" en la que muchos de ellos aspiran ascender hasta llegar a ser pastores, y para lo cual asisten a clases, discipulados o cursos de teología. Existe entonces la perspectiva de ascenso individual. Hacer parte de esa "escalera" significa asumir roles activos y de liderazgo. Esto es contrastado con la rigidez y exclusividad de la organización eclesial católica, donde el sacerdote se percibe como una figura lejana.

La mayor parte de las personas entrevistadas recuerdan (o imaginan, en el caso de las más jóvenes) con desagrado una época en que las autoridades católicas (curas y monjas principalmente) dominaban sus vidas de manera "autoritaria" — según sus palabras-, tanto a través de su poder parroquial, como a través de las instituciones educativas administradas por la Iglesia. Lamentan también que en el pasado no había ninguna otra opción para "conocer de Dios". Para estas personas, el haber podido acceder a la Iglesia cristiana es vivido como una fortuna, un derecho adquirido y la expresión de su libertad personal.

6 Esto es constatado en otros países por Luhrmann (2012, p. 373): "Muchas de las iglesias evangélicas creen que sus devotos pueden interactuar directamente e inmediatamente con Dios".
Así, el salir de una tradición familiar católica hacia una Iglesia cristiana es una decisión que el individuo toma de manera individual. Esto, como veremos, hace parte del proceso de individualización que caracteriza a la modernidad tardía. Como señaló Elias en La sociedad de los individuos (1990), la modernización va a la par con un aumento de las posibilidades para la elección individual. Las obligaciones heredadas o por pertenencia a una tradición familiar ceden ante el ideal de ser un individuo que decide el rumbo de su propia vida: la elección se convierte en un imperativo. El cambio hacia la Iglesia cristiana se puede entender como parte de la expansión de una modernidad reflexiva (Beck et al., 2001), proceso en el cual la individualización juega un papel central. Beck precisa (2001) que esta individualización no significa la destrucción de la sociedad ni tampoco que los sujetos se hayan separado completamente del entramado sociocultural que les brinda sustento material y simbólico para vivir. La individualización significa en realidad la "compulsión de encontrar y buscar nuevas certezas para uno mismo y para quienes carecen de ellas" (Beck, 2001, p. 29). Con la modernización, el sujeto está entonces cada vez más compelido a ser el director de su propia biografía, a ser quien diseña para sí mismo su vida, sus compromisos, sus relaciones sociales. La vida se convierte en una biografía por elección (Beck, 2001, p. 30) o, en términos de Giddens (1997), en una biografía reflexiva. Según este principio, todo lo que se haga debe ser producto de una decisión consciente.

Por demás, añade Beck (2001), lo que el sujeto lleva a cabo en su vida es percibido como parte de un proceso de construcción de la propia individualidad, de ese yo individual que se percibe como algo único. El ideal moderno es el de la construcción de un "Yo" que se concibe como el centro del universo y principal eje de las preocupaciones y motivaciones. La individualización de la modernidad tardía supone entonces un actor que toma todas sus decisiones concibiéndose a sí mismo como "el centro de las cosas" (Beck, 2001, p. 31). Las decisiones deben ser tomadas en función del Yo y para el Yo. Beck demuestra que esta perspectiva evidentemente desincentiva las formas tradicionales de vida, entre las cuales debemos 
considerar, por supuesto, al catolicismo tradicional. De igual manera, el individuo rechaza cualquier imposición que provenga de una tradición familiar, al ser el catolicismo parte fundamental de esta última.

El rechazo por formas tradicionales de vida parecería no ser, a primera vista, una tendencia que permita explicar el paso del catolicismo al pentecostalismo, dado que este último también suele ser considerado una referencia tradicional. En efecto, los cristianos evangélicos constituyen una población que se reclama heredera directa de una espiritualidad de más de dos mil años de antigüedad. Pero no hay contradicción aquí, ya que, si bien los evangélicos dicen querer volver a las enseñanzas tradicionales, sus formas de vida y las comunidades que construyen no son en absoluto tradicionales sino completamente modernas, y la Iglesia pentecostal no es una institución tradicional, sino una de creación muy reciente en la historia de la modernidad.

La tradición como una herencia familiar o comunitaria que impone una cierta forma de vida ajena a la voluntad de los individuos es contraria al principio de individualización que hemos señalado. La comunidad cristiana puede ser, en ciertos sentidos, tradicionalista, en la medida en que reivindica más que nunca la tradición cristiana. De hecho, algunas de estas modernas iglesias cristianas desean mantener esa tradición lo más intacta posible ${ }^{7}$. Sin embargo, esta tradición no es percibida por los individuos como una obligación ni un manto que se impuso sobre sus cabezas cuando nacieron sin dejarles ninguna opción. La tradición, en estos contextos modernos, se acepta y se vive en la medida en que se perciba como un recurso al cual el individuo puede acceder si así le place. La tradición se convierte así en un medio más para construir la propia biografía, para ayudarse en el proceso de autoconstrucción, el cual es propio de la individualización.

7 Una tradición que, como suele ocurrir, es "inventada" (Hobsbawm y Ranger, 1983); es la reconstrucción e interpretación contemporánea de lo que sería la tradición antigua. En palabras de Giddens (2001), “la modernidad ha reconstruido la tradición a medida que la ha disuelto" (p. 75).

\section{Soportes para el individuo moderno}

Cuando un individuo llega por primera vez a la Iglesia, recibe una calurosa bienvenida por parte de los asistentes, quienes se muestran amables y dispuestos a conversar con él, le explican en qué consisten las actividades de la comunidad, lo pueden invitar a tomar un café o incluso, un poco más tarde quizás, a comer en sus casas. Igualmente, los sujetos entrevistados resaltan el apoyo fuerte y personalizado que recibieron desde que llegaron a la Iglesia cristiana, lo cual - según ellos- nunca habían encontrado en la Iglesia católica. Así, contrariamente a las explicaciones economicistas a propósito del éxito de estas iglesias, es necesario recalcar que este apoyo cristiano no es principalmente material (y mucho menos monetario), sino social, cognitivo y afectivo, y proviene no solo de los líderes de la Iglesia, sino de los mismos creyentes: "Padre, hoy te pido que nos ayudes a nosotras como madres espirituales a estar ahí cuando ella nos necesite, nos des palabra de ciencia, palabra revelada para guiarla", pedían dos fieles en relación con una neófita.

Quienes integran la Iglesia por primera vez son considerados "bebés espirituales". Durante unos meses, estos "bebés" son muy tenidos en cuenta, se les pregunta por su situación personal, se les ofrece orar por ellos, etc. Esto obedece en parte al hecho de que cada persona se siente responsable por la salvación de las almas que Dios puso a su alrededor. Esto tiene como consecuencia un apoyo y atención individualizados. Nada de esto ocurre en la Iglesia católica; como varias personas dijeron, allí "a nadie le importa quién es uno ni qué problemas tiene". Una madre cristiana cuenta quellevó a su hija enferma a una Iglesia católica, donde el cura le dijo que no tenía nada que hacer por ella. En cambio, en la Iglesia cristiana la comunidad la rodeó y le dijo que iban a orar por su hija. "En ese momento empecé a sentir a Dios en mi interior", dice la madre, convencida de que seguirá yendo a la Iglesia cristiana.

Los seguidores sienten tener una misión y un lugar que les permite sentirse integrados y motivados, lo cual dicen no haber encontrado cuando eran católicos. Existen además múltiples actividades 
que realiza la comunidad cristiana por fuera del culto, y cuya frecuencia e intensidad no se ven en medios católicos. La Iglesia cristiana se convierte en una verdadera plataforma de socialización para las personas, una razón más por la cual todo esto no se puede limitar a una simple cuestión económica, como comúnmente se piensa.

La comunidad evangélica proporciona referencias prácticas que permiten encontrar el "sentido de la vida", como varias personas afirman. Iglesias como Manantial constituyen "comunidades de convicción que contrarrestan la propagación pandémica de las crisis de sentido" (Berger y Luckmann, 1997, p. 63), así como contrarrestan la desorientación, la soledad o el vacío emocional. Sabemos que las referencias de sentido "seculares" son ahora inestables e inciertas (Berger y Luckmann, 1997) y que reina una cierta "inseguridad ontológica" entre las personas, producto de los procesos modernizadores que afectan “todos los ámbitos vitales y sociales" (Beck, 2009, p. 94). Frente a esto, el fundamentalismo religioso evangélico (como otros fundamentalismos) deviene una respuesta muy moderna para compensar esa inseguridad, desorientación e incertidumbre relacionadas con hechos objetivos como el debilitamiento de los lazos familiares y sociales, la multiplicidad de marcos referenciales que genera el pluralismo o la precariedad laboral, entre otros (Bauman, 1998).

\section{Los cultos}

Con el fin de comprender las motivaciones de las personas al adherirse a una Iglesia, es indispensable tener en cuenta lo que sucede en sus cultos ya que este es el principal espacio colectivo donde se construyen sentidos, emociones, vínculos sociales, etc. A continuación, presentamos una breve descripción esquemática de dichos cultos.

Muchos individuos de la población estudiada dicen asistir mínimo dos veces por semana al culto y afirman leer la Biblia a diario. Testifican además que ahora sí entienden lo que oran, en contraposición a lo que les ocurría en la Iglesia católica, cuando "solo repetían [las oraciones], sin entender absolutamente nada". Según diferentes personas, el mensaje de la misa "entraba por un oído y salía por el otro", les era indiferente, intrascendente; ir a la Iglesia católica no significaba para ellas prácticamente nada más que una obligación vacía, luego de la cual volvían a sus casas "sin sentir ningún cambio". El cambio, como veremos, se articula a la noción de progreso individual, la cual constituye uno de los principales valores de la modernidad tardía y permea cada vez más amplios sectores de la sociedad colombiana.

Típicamente, un culto cristiano inicia con alabanzas y cantos destinados a Dios, con frases como "levantamos nuestras manos exaltándote, Señor", "Tú eres grande, poderoso y maravilloso", "no hay nadie como Tú", "mereces la gloria", "te amo, Señor". Estas alabanzas se caracterizan por la utilización de música muy animada, con ritmos modernos, bailables y a altos volúmenes. Esto es particularmente llamativo y espectacular en el culto del domingo o día de cultos familiares ${ }^{8}$, que es cuando hay mayor afluencia de adeptos, especialmente de niños y adolescentes. La música del culto de este día suele ser interpretada por bandas en vivo, utilizando tecnología de punta en el sonido y las luces. Considerando lo anterior, esta etapa puede asemejarse en ciertos aspectos a un concierto de música de tipo pop-rock, solo que las letras de las canciones son claramente religiosas. También se pueden observar bailarines que acompañan a los músicos al frente del escenario, mientras los asistentes, en general, también cantan fuertemente, levantan sus manos y bailan. Esto otorga al culto un carácter lúdico y animado que los seguidores aprecian y dicen jamás encontrar en las misas católicas.

En los cultos se invita a los fieles a ser activos en cuanto a su corporalidad y expresividad. Como explica un pastor, "el clamor nunca se hace de manera pasiva", sino "de forma agresiva contra las huestes de maldad", "hoy declaramos que todos los acá presentes no se quedarán en sus sillas pasivamente como

8 Existen diferentes tipos de cultos en diferentes horarios y días de la semana, por ejemplo los cultos de los viernes en la mañana, denominados "Ayuno" y "Culto de Milagros". Sin embargo, para no extendernos demasiado, no entraremos en los detalles específicos de cada uno de estos tipos. 
religiosos, ellos avanzarán; los convertirás en guerreros". La música, el canto, la marcada gestualidad colectiva constituyen lo que Weber (2002, p. 329) denominará los aspectos "orgiásticos y mímicos del culto religioso", los cuales inciden en una intensa emocionalidad y que no son tan marcados en las misas católicas. Así lo aseguran los cristianos, para quienes "los religiosos" (es decir, los católicos) son demasiado "pasivos" y llevan a cabo una "oración liviana" que no tiene verdaderos efectos en la vida humana.

En un momento posterior al culto puede haber un cambio de pastor o pastora, quien no deja de referirse a Dios pronunciando frases como: “Tú eres mi estandarte [...], declaramos la presencia tuya en este lugar [...]. Tú eres quien nos saca de la desesperación". Para las personas, este momento de sentir la presencia de Dios es evidentemente de una gran trascendencia, lo cual se acompaña con movimientos corporales como levantar los brazos, dirigir la cabeza hacia arriba y gesticular hablándole a Dios. La expresividad y los movimientos permiten incrementar el sentimiento de la experiencia religiosa. Durante estos momentos intensos de trascendentalidad puede ocurrir una suerte de éxtasis en el que algunas personas comienzan a "hablar en lenguas". La glosolalia es, para los pentecostales, una manifestación ostensible de que el Espíritu Santo está allí mismo, en el cuerpo de una persona, hablando a través de sus labios.

En otro momento del culto también se invoca el poder divino para que se cumplan los deseos de los creyentes. Los pastores piden en voz alta, por ejemplo, para que "toda obra de maldad u obstáculo se desvanezca" o para que "los inversionistas en el reino sean prosperados". Se recuerdan igualmente los males y sufrimientos de las personas, y luego se pronuncian frases como "hoy los demonios serán expulsados [...], repitan conmigo: mis problemas tienen solución", lo cual exalta a la multitud con la esperanza en un futuro mejor. Por otro lado, el hecho de hacer referencia a casos específicos de fieles que han resuelto sus problemas, han "salido adelante" y ahora "caminan sobre el mal" es algo que refuerza las esperanzas en un futuro mejor, y además cumple una función afectivo-emocional importante, ya que logra que las personas sientan que son tenidas en cuenta y encontrarán apoyo en ese contexto social.

Cuando se pide a Dios y se invoca su presencia, los adeptos generalmente están de pie; muchos cierran los ojos, levantan sus puños - a modo de lucha-, algunos salen de sus puestos y caminan por el lugar. De nuevo, una intensa gestualidad refuerza los sentimientos y la convicción de que todo aquello tendrá efectos ostensibles en sus vidas. El pedir favores a una divinidad no es, por supuesto, único de los cristianos ${ }^{9}$. En el catolicismo popular sabemos que esto es muy frecuente. La diferencia es que acá son cientos y a veces miles de personas que invocan juntas y al unísono el poder de Dios, además de que se trata de una experiencia que puede ser vivida varias veces a la semana.

En otro momento del culto, el pastor procede a leer algunos pasajes de la Biblia ${ }^{10}$. La gran mayoría de los presentes posee el Libro y lo lee también; en caso de que alguien no lo tenga, puede leerlo con otra persona que generalmente estará dispuesta a compartirlo - aún si se trata de un desconocido- o puede leer los pasajes proyectados en las pantallas electrónicas con que cuenta la iglesia. El pasaje bíblico es interpretado por el pastor, quien explica el mensaje de manera "más desmenuzada", como dicen las adeptas, es decir, muestra la relevancia específica de cada pasaje para la vida cotidiana y según el contexto local o nacional. Se habla, por ejemplo, de la violencia familiar, del divorcio, la drogadicción, de la corrupción de los políticos, de la pobreza, etc. En conexión con las intervenciones del pastor, muchos adeptos subrayan la Biblia y toman nota en cuadernos propios con el fin de "aplicar el mensaje en su vida diaria". Esto muestra una marcada apropiación del texto bíblico, algo que tampoco ocurre entre los católicos. En efecto, para los cristianos, antes de su llegada a la Iglesia evangélica, los mensajes de la Biblia les parecían totalmente distantes y sin relevancia.

9 Es un caso típico de lo que Weber $(2002$, p. 343) denominó “coerción divina".

10 La biblia cristiana es muy similar a la biblia católica, solo que omite algunos de sus libros (como los Apócrifos) y suele corresponder a la traducción realizada en los siglos xVI y xVII por Casiodoro de Reina y Cipriano de Valera, revisada posteriormente en 1960. 
En los cultos, el pastor principal recuerda que es importante "difundir la palabra" y llevar a otros invitados a cultos: "estamos aquí para servirle a Dios, entonces tenemos que predicarle a nuestras familias, a nuestros amigos, a todos los que conozcamos, porque queremos que ese conocimiento lo tengan todos". Esto es un poderoso mecanismo para la expansión de este tipo de iglesias, y algo que muy rara vez ocurre entre los católicos. Es así que una buena parte de los cristianos entrevistados llegaron a la iglesia por invitación de alguno de sus conocidos ${ }^{11}$.

Para dar la bienvenida a los recién llegados, en cada culto hay un momento especial: primero, son invitados a pasar al frente y luego el pastor le pide a toda la comunidad que ore por ellos; a los neófitos se les incita a repetir frases como: "yo necesito a Dios, yo quiero un cambio, yo quiero rendir mi vida a Dios. Dile a Dios: a partir de hoy te entrego mi vida para que Tú la gobiernes". El pastor les dice que con este día comienza un nuevo tiempo para ellos, y que serán acompañados por todos los demás hermanos cristianos. Acto seguido, los neófitos son conducidos a un cuarto aparte donde se les piden sus datos personales, para así contactarlos después y asegurar su retorno. Estos mecanismos de inclusión, claramente, no tienen lugar en las iglesias católicas.

Durante el culto también se recoge el dinero de las "ofrendas", "siembras" y "diezmos", los cuales son introducidos en sobres con un formato especial - tipo formulario- donde las personas anotan sus nombres completos, su teléfono, el pastor de su distrito, las cantidades que asignan a las diferentes causas, etc. En el sobre se lee: "El que siembra escasamente, escasamente cosechará", una metáfora bíblica que incita a los cristianos a dar más dinero, para recibir más de Dios. Después de la recolección de los dineros, toda la Iglesia extiende sus manos hacia los alfolís (sostenidos por los diáconos) con el

11 Así se expresa, a nivel personal, una política de activismo expansivo que implementan las iglesias evangélicas en todo el mundo (Martin, 2002). En el mismo sentido, Beltrán (2005) nota que los cristianos suelen estar dispuestos a compartir su experiencia de conversión con otras personas de su entorno, lo que contribuye a aumentar el número de interesados. fin de "consagrar" tales recursos, invistiéndolos de un poder sobrenatural.

La fuerza del pensamiento mágico se evidencia también cuando, durante el culto, el pastor pide a todos los adeptos que están enfermos a que vayan frente a él, para luego pronunciar sentencias como: "Espíritu de Dios sana y libera. Sana a tu pueblo. Sana y revélate en ellos; aún a los que están metidos en el infierno con su descendencia, muéstrales el camino, quítales las cadenas, quítales los yugos". Acto seguido, el pastor sopla las caras de los sujetos $y$, uno a uno, se desvanecen y permanecen tendidos en el suelo por unos minutos con sus ojos cerrados, llorando o temblando. Según varias de las entrevistadas, este es el momento en que el Espíritu Santo entra en las personas de una manera tan fuerte que las tumba al piso y es así como las sana o las libera de sus males (el demonio). La puesta en escena de este tipo de actos que, para los individuos, son la manifestación de un inmenso poder sobrenatural, no ocurre tampoco en las misas católicas.

Al finalizar el culto, antes de que las personas salgan de la iglesia, se realizan además algunos anuncios sobre las actividades que la comunidad realiza, tales como retiros, encuentros, cursos, etc. Estas actividades por fuera del culto tienen bastante importancia para las personas, ya que las integran más a la comunidad y son fuente de diversión e instrucción. Por demás, los grupos de amigos cristianos salen a comer, a paseos, a conciertos, etc. De hecho, para muchos, esta comunidad se convierte en su principal o único medio de socialización, y no es nada raro encontrar parejas de matrimonio cuyos cónyuges se conocieron en la iglesia. Muchas de aquellas actividades que se realizan por fuera del culto están dirigidas a categorías específicas de personas, como son los jóvenes, las parejas casadas, los(as) solteros(as), las mujeres, los hombres, los adultos mayores. Esto permite aún mayor integración por parte de los adeptos, quienes sienten que pueden encontrar en la iglesia la respuesta a cada una de sus inquietudes específicas, así como el reconocimiento comunitario de sus condiciones particulares. 


\section{Análisis alrededor de tres valores de la modernidad tardía presentes en las motivaciones cristianas}

\section{Libertad}

Hemos visto que los cristianos viven su nueva religiosidad como la expresión de una elección libre. La idea de una religión impuesta por los padres o por la tradición no tiene acogida entre la población. Varias personas entrevistadas recuerdan con amargura que fueron obligadas a ir a la misa católica durante años cuando eran más jóvenes. Una entrevistada añade, por ejemplo, que "a uno en la [Iglesia] católica lo bautizan cuando es un bebé y no entiende nada, mientras aquí [en la Iglesia cristiana] yo me bauticé y sé por qué lo hice". Casi todo lo relativo al catolicismo tiene connotaciones de obligatoriedad, es decir, se concibe como la violación del derecho (santificado en la modernidad) a la libertad personal.

Lo anterior se inscribe en el proceso general de individualización que caracteriza la modernidad tardía y que se manifiesta no solo en el campo de lo religioso. Como señala Beck (2009), se trata de la radicalización de la libre elección por parte del individuo, de "la institucionalización de la obligación de decidir individualizadamente" (Beck, 2009, p. 126) acerca de cualquier aspecto de la vida propia. Esta individualización "vacía de contenido la institucionalización del 'clasisismo' religioso y el 'nacionalismo' de las iglesias de la primera modernidad” (Beck, 2009, p. 94). Ello quiere decir que los individuos no están dispuestos a obedecer a los designios de una institución religiosa "clásica" y propia de la sociedad nacional de antaño. En América Latina, es claro que la Iglesia católica ocupó en el pasado el lugar de esa institución "clásica" y "nacional". Sin embargo, con el avance de la modernidad, señala Luckmann (1973), ocurre una particular división "entre el modelo 'oficial' de religión y los sistemas individuales predominantes de 'significancia última"' (Luckmann, 1973, p. 93). Este es el contexto en el que el cristiano abandona la Iglesia católica de sus ancestros y busca nuevas formas de religiosidad según sus propios intereses y criterios, y sigue el imperativo de búsqueda individualizada que se impone en el proceso de modernización.

En nuestros tiempos, todo consumidor tiene el derecho y el deber de escoger lo que quiera dentro de la oferta (religiosa). Evidentemente, desde Durkheim (1982, pp.395-396) sabemos que en la realidad no hay tal individuo autónomo que decide en qué creer de manera totalmente independiente del medio social en el que se ha formado. No obstante, las personas buscan ejercer el ideal de independencia individual y evitan sentirse atadas u obligadas por una institución religiosa que no eligieron ellos mismos en la edad adulta. Cada cual debe acercarse a las creencias y prácticas que más se acomoden a sus preferencias.

Si bien asistir a la iglesia cristiana es percibido por los sujetos como una manifestación de la libertad individual, en estos medios también se maneja otro sentido de la palabra "libertad", el cual definitivamente no corresponde con el de "hacer lo que uno quiera". Así, "entregarse a Dios", como se aspira entre los evangélicos, es un medio para alcanzar la verdadera libertad. A través de la verdad revelada, uno se hace "libre de maldiciones", de la ignorancia, de las tentaciones del demonio, del pecado, "del mundo", es decir, de lo mundano y sus ataduras ${ }^{12}$.

Seguir la palabra implica obedecer ciertas restricciones, purificarse de vicios como el cigarrillo, las drogas o el alcohol, liberarse de tendencias "inmundas" como la homosexualidad o la fornicación, alejarse de prácticas mundanas como bailar en fiestas o escuchar música pagana. Acatar las prohibiciones se convierte en un medio para alcanzar una libertad sacralizada. Se debe entregar la vida a Dios para que Él la gobierne y la lleve por el camino correcto y puro, con lo cual se evitan los errores que puede cometer el yo dentro de su ignorancia y falibilidad. De manera aparentemente paradójica desde una lógica liberal, el seguir las reglas y "entregar su vida para que Dios la gobierne" son medios para la liberación. A la pureza del alma y a la libertad se

12 Lo mundano corresponde aproximadamente a lo profano, lo banal, lo inferior, y que se opone a lo sagrado, lo puro, lo superior, en aquella dicotomía que Durkheim (1982) consideraba como fundamental en el fenómeno religioso. 
accede a través de una moral religiosa que — según los propios sujetos - no tienen los católicos. En efecto, la iglesia cristiana es más restrictiva y estricta con respecto a las normas de conducta:

en la católica, por ejemplo, uno sabe si mucho los diez mandamientos, mientras acá uno tiene todo más claro. Uno sabe que tiene que vivir una vida sin groserías, sin rencores, sin odios, sin infidelidades y salirse del mundo [profano].

Recordemos que las personas insisten en que ser cristiano es seguir un "estilo de vida", es decir, cambiar muchos comportamientos en la cotidianidad; no basta con ir a misa los domingos. Varias cristianas afirmaron, por ejemplo, que las católicas son "infieles y mentirosas". Ser católico es "ser de mundo", tener una moral demasiado laxa y no seguir realmente los principios de la Biblia ${ }^{13}$. La búsqueda de guías claras y fuertes es también una consecuencia de la modernidad tardía y su individualización. Como Bauman (2000) señala, la modernización recientemente se acompaña de un proceso de desregulación en los ámbitos de la intimidad personal (p. 135). La libertad individual se vuelve desorientación y responsabilidad angustiante por el éxito o fracaso. Bauman añade que el individuo vive permanentemente el riesgo de equivocarse en sus decisiones; el deber de afrontar la contradicción y el riesgo se individualizó, por eso algunos individuos, especialmente aquellos que están en situaciones de fragilidad e inseguridad, buscan guías fuertes que les devuelvan confianza y seguridad en sí mismos.

La libertad está también representada en lo que los creyentes llaman la "conexión directa con Dios sin ningún tipo de intermediario". Estas personas sienten entonces que están en total libertad para "hablar con Dios directamente" y en sus propios términos. No hay pues la sensación de que existe una intermediación por parte de un sacerdote, lo cual se considera un aspecto negativo del catolicismo. En el mismo sentido, otra persona afirmaba: "yo no quiero una religión, quiero una relación contigo [Dios], una amistad". En efecto, las cristianas dicen vivir

13 El mismo tipo de afirmaciones sobre los católicos se observa entre los conversos al Islam en Colombia (Sarrazin y Rincón, 2015). una "relación con Dios" íntima e individualizada, aparentemente independiente de la comunidad y de la autoridad eclesial.

En lo anterior vemos una contradicción que, según Beck (2009, p. 116), está presente en el cristianismo desde sus orígenes: una comunidad que busca institucionalizar sus reglas y al mismo tiempo promueve la individualización y la autonomía. ¿Cómo se concilian estos dos principios? Aunque más adelante volveremos sobre esto, cabe aclarar por ahora que la Iglesia cristiana, adaptada como lo está a la modernidad liberal, ejerce su influencia sobre los individuos no a través de la coacción $\mathrm{u}$ obligación, sino principalmente a través de la seducción, apelando considerablemente a las emociones de los sujetos.

\section{Emoción}

La orientación que brinda la Iglesia no está basada simplemente en códigos de conducta o discursos sobre la verdad. La emoción religiosa (analizada más adelante) también es central para orientar a las personas en su vida cotidiana y es una poderosa fuente de inspiración (Riis y Woodhead, 2010, p. 94). "Ahora me levanto contenta por las mañanas porque encontré la razón de vivir", o "en el culto uno se llena de ánimo, de motivación, de ganas de vivir", son frases que indican la estructuración cognitiva, emocional y social que encontraron las personas al frecuentar la comunidad cristiana. Esas referencias fuertes no son encontradas en las "aguas tibias" y los rituales desencantados que las personas ven en el catolicismo tradicional. Esta búsqueda de emociones fuertes es también un rasgo generalizado en la modernidad tardía. Según Bauman (2007), una de las características de la sociedad de consumo en la que vivimos, es "el enaltecimiento de la novedad y la degradación de la rutina” (p. 175). Este autor señala que, si bien en la modernidad temprana se pretendía que el hombre fuera cada vez más racional y menos emocional, en esta modernidad tardía se valora cada vez más la vivencia de emociones intensas.

En consonancia con lo anterior, los cultos evangélicos plantean siempre nuevas actividades y horizontes para las personas. Para los cristianos 
"el culto es algo que uno disfruta [...], en cambio la misa es aburrida". "Después del culto uno se siente mejor, más motivado [...]. De la iglesia católica, uno sale igual que entró, o hasta más triste". Cuando los entrevistados hacen este tipo de afirmaciones, se evidencia que los cultos generan en ellos fuertes emociones valoradas positivamente. Como vimos, la música, la danza, la expresividad corporal, la disposición espacial y hasta las luces contribuyen a exaltar esas emociones. Esto juega un papel central en la experiencia religiosa, la cual no puede limitarse analíticamente a una doctrina discursiva; como afirman Riis y Woodhead (2010, p. 13), "religious emotion is expressed through ritual, music, art and architecture because rationalized language does not suffice".

Las misas católicas, en cambio, son descritas como insulsas y monótonas, como "reuniones planas" donde "no pasa nada" y "no se siente nada", según varias creyentes. Incluso considerando características como el espacio físico, la oscuridad, la quietud y la deficiente acústica de la mayoría de iglesias católicas, estas no corresponden con los gustos de los sujetos: "entrar a la iglesia [católica] era entrar a un edificio frío, a un templo oscuro, lleno de imágenes, donde no había nada que tuviera vida", afirma uno de ellos. En cuanto a los discursos públicos evocados por los pastores en los cultos y a través de los medios masivos de comunicación, estos también están cargados de emocionalidad, ya que invitan a imaginar que todo lo malo es expulsado o dejado atrás, y que vienen estados de abundancia, éxito y bienestar; paralelamente se evoca la idea de una divinidad inmensamente poderosa, presente $y$ cercana al yo.

En efecto, en el "régimen emocional" (Riis y Woodhead, 2010, p. 10) que se aplica en el medio cristiano, es central la intensidad con la que se concibe a Dios. A propósito, una mujer nos decía: "en la Iglesia cristiana le enseñan a uno a conocer la fe, a andar con el Espíritu Santo, a sentirlo dentro de uno, lo que uno nunca siente en la católica". Otra persona explica que "era como si tuviera los ojos vendados hasta que llegué aquí y me encontré realmente con Dios". Aunque evidentemente en los discursos católicos la figura de Dios también es importante, el Dios católico es lejano y la persona no siente su presencia de manera intensa, directa y frecuente, como sí ocurre en el medio estudiado.

La idea de "Dios como un amigo" refuerza aún más aquella sensación de cercanía con la divinidad. En la Iglesia católica, según los sujetos, "Dios está allá lejos, arriba, es inalcanzable [...]. Además, siempre está el cura que nos dice cómo debemos hablarle a Dios". Para el cristiano, el individuo no reza como en la iglesia católica, sino que "conversa con las palabras que uno mismo conoce". Por otro lado, "el Señor sabe lo que usted necesita y trata de manera distinta con cada uno [de nosotros]". Esto permite a los individuos sentir que su experiencia trascendental es personalizada, única e irrepetible. Ello lo contrastan con el catolicismo, donde todo el mundo solo repite "mecánicamente" ciertas oraciones predeterminadas y "universales", como el padre nuestro y el ave María. El catolicismo sería entonces una suerte de religión impersonal que no llega a tocar las fibras íntimas de las personas.

La emocionalidad está ligada a la corporalidad. En la población estudiada se insiste en que no se trata realmente de creer en Dios, sino de sentirlo en el cuerpo. Muchos de ellos coinciden en afirmar que ahora sienten "un Dios vivo que está dentro de uno" ${ }^{14}$. Así, una mujer asegura que cuando llegó por primera vez a Manantial "se desmoronó" y sintió que Dios la "levantaba"; afirma además que desde ese momento empezó a conocerlo e imaginárselo de otra manera. Todos estos relatos demuestran la importancia de las sensaciones y la imaginación en el medio cristiano. Como dice Hervieu-Léger (2000), en el contexto contemporáneo la emoción religiosa es más visible que nunca; estas formas de religión que hablan a los corazones mas no al intelecto son las que atraen a la mayor parte de conversos actualmente, incluso en la secular Europa. En general, el pentecostalismo ha integrado y capitalizado esta tendencia moderna al apelar sistemáticamente a las emociones intensas de sus

14 Como afirma Luhrmann (2012, p. 373) a propósito de otras iglesias evangélicas: "Ios fieles experimentan a Dios directamente en sus cuerpos". (Nuestra traducción). 
adeptos, lo cual se considera una de las causas de su crecimiento a nivel mundial (Martin, 2002).

\section{Progreso}

En la sociedad colombiana actual es de gran importancia el imperativo personal de "progresar", "avanzar", "salir adelante", "evolucionar", etc. Esto se inscribe en el ethos del progreso que caracteriza a la modernidad y que ha sido interiorizado por parte de los individuos, llevándolos a una búsqueda constante de transformación individual. El yo debe progresar. De nuevo, vemos que con el proceso de modernización de los sectores populares se acrecienta también su proceso de individualización, esta vez manifiesto a través del ideal de progreso individualizado. En consonancia con lo anterior, en el medio evangélico se observan frecuentemente mensajes esperanzadores que instan al individuo a "salir adelante" y auguran el éxito personal ${ }^{15}$. Para estas personas, no es atrayente la idea del Dios católico que invita a la resignación, y que en lugar de impulsarlas a "salir adelante", las hacía sentir "malas" y "pecadoras", según narran algunas de ellas. A diferencia de lo que se encuentra en el catolicismo, el Dios evangélico no es imaginado principalmente como un poder castigador, sino como un poder que permite alcanzar la bienaventuranza y recibir todo tipo de "bendiciones" asociadas al progreso individual. De ahí la importancia de los "testimonios" públicos llevados a cabo en los cultos y en los medios de comunicación, donde las personas narran, por ejemplo, que por el poder divino dejaron de fumar, de tomar alcohol, dejaron las "malas compañías", y ahora estudian, trabajan, sacaron adelante sus proyectos y son personas exitosas.

En esta comunidad el sujeto es incitado constantemente a imaginar que sus problemas personales acabarán, que "viene algo mejor", que con Dios todo se puede. Este es un Dios del progreso individual, un Dios cercano que "quiere ayudarte". Este progreso, cabe aclarar, no se manifiesta meramente a través de milagros que caen del cielo. No se trata de una simple "coerción divina" (Weber, 2002) donde se reza para

15 Es inevitable recordar aquí la tesis de Weber (1969), en la que se relaciona la ética protestante con el desarrollo del capitalismo. pedir favores a un Dios distante, y mucho menos es la aplicación del tradicional adagio: "el que peca y reza, empata" "Primero hay que pedirle la dirección a Dios, antes de hacer cualquier cosa, para que te guíe, para que te abra puertas, para que seas bendecida y luego seguir sus consejos", testificaba una creyente. De esta manera, las bendiciones vienen gracias a una transformación del propio sujeto quien, luego de entregarle su vida a Dios, es guiado por Él y es transformado en una persona trabajadora capaz de alcanzar el éxito. Este principio, según Riis y Woodhead (2010, p. 13), corresponde con tendencias transnacionales de la espiritualidad contemporánea, donde se busca una mejoría o transformación interior. Dios nos transforma y gracias a Él triunfamos y progresamos. Por eso, según esta lógica, es clave asumir el estilo de vida cristiano y ser constante en ello. Los católicos, en cambio, estarían desconectados de Dios, no le entregan a Él sus vidas y, por ende, tampoco siguen las normas de comportamiento y son demasiado laxos en su estilo de vida. Como dice una cristiana "en la católica uno no sabe qué es lo que debe hacer [...], no sabe qué es lo bueno y qué es lo malo". La desorientación y la permisividad vivida en los medios católicos serían entonces algunas de las razones por las cuales los individuos allí no progresan.

La Iglesia católica insiste con sus mensajes de resignación ante el sufrimiento y la desgracia, los cuales son contrarios a la idea moderna de transformación para el progreso, de lucha frente a la adversidad. Para los sujetos, la idea de que en la muerte gozaremos de un cielo eterno no basta para motivarlos. Si bien el mensaje evangélico no excluye la idea del paraíso después de la muerte, insiste mucho más en la posibilidad de cambiar las condiciones de vida actuales y gozar de grandes bendiciones sin esperar hasta la muerte. Este deseo de resultados a corto plazo también corresponde con la valoración de la inmediatez que se difunde en la modernidad tardía.

\section{Conclusiones}

Las nociones de libertad, emoción y progreso personal señalan conceptos cruciales en las motivaciones de la migración religiosa del catolicismo 
al pentecostalismo. Pero estos conceptos, evidentemente, no se deben entender como valores limitados a una comunidad religiosa aislada de las tendencias dominantes en la modernidad. Lejos de una dicotomía clásica que opone la religión a la modernización como si fuesen mutuamente excluyentes, lo que vemos acá es una forma de religiosidad que ha crecido precisamente porque surge en la modernidad y se adapta a ella.

La sociedad liberal impone el juego de la libre competencia incluso en el campo religioso, donde los ganadores se definen en función de los "consumidores" que logren atraer y seducir. La iglesia pentecostal organiza impresionantes rituales, exalta las emociones, suscita fuertes sentimientos relacionados con la sanación, la grandeza y el poder; es mucho más que conceptos abstractos, evoca trascendentalidad, genera esperanza, favorece la integración y la interacción. Con este tipo de ofertas, la Iglesia atrae individuos que reclaman la posibilidad de escoger libremente y que buscan la emancipación con respecto a las pertenencias heredadas y las tradiciones obligatorias. En ese contexto, la Iglesia católica se convirtió en símbolo de una pertenencia meramente nominal, una herencia obsoleta, una institución distante, fría y, sobre todo, que obliga a los individuos a seguir códigos de conducta y rituales que carecen de sentido para ellos.

La Iglesia evangélica, a pesar de que podemos caracterizarla como fundamentalista, logra presentarse ante la población no como un conjunto de obligaciones, sino como una fuente indiscutible de orientación, de manera que el individuo se siente apoyado y seguro de estar al fin en la senda correcta, del lado del poder absoluto, y con la clave para transformarse y progresar en esta vida. En tiempos en que las certezas y los vínculos humanos se debilitan bajo una modernidad de pluralismo, liberalismo e individualización, la propuesta pentecostal es tan asertiva y fuerte emocionalmente hablando que no deja lugar a dudas: los sentimientos de indefensión, incertidumbre, inseguridad y desorientación disminuyen para el cristiano. Lo mismo no ocurre, en cambio, en lo que es considerado las "aguas tibias" del catolicismo.
De igual manera, la Iglesia evangélica logra hábilmente disimular sus jerarquías, al plantear sus relaciones en términos de horizontalidad y cercanía personalizada (como lo quieren también las tendencias más actuales), mientras que la relación con los sacerdotes católicos es vista en términos de verticalidad y distancia impersonal. Para los cristianos, los pastores no ordenan sino que guían en un proceso de acercamiento a Dios. La normatividad eclesial en este caso no es percibida como un código de conducta de carácter obligatorio, ni es vista negativamente como una limitación, sino como una opción para alcanzar aún más libertad individual y bienaventuranza. En efecto, el cristiano busca en la Iglesia las pautas y las fórmulas para liberarse de las cadenas que le impiden realizarse como persona.

\section{Referencias}

Bastian, J. P. (2004). La recomposición religiosa de América Latina en la Modernidad Tardía. En J. P. Bastian (ed.), La modernidad religiosa: Europa latina y América Latina en perspectiva comparada (pp. 155174). México D.F.: Fondo de Cultura Económica.

Bastian, J. P. (2007). De los protestantismos históricos a los pentecostalismos latinoamericanos: análisis de una mutación religiosa. En C. Tejeiro, F. Sanabria y W. M. Beltrán (eds.), Creer y poder hoy (pp. 453-468). Bogotá: Universidad Nacional de Colombia.

Bauman, Z. (1998). Postmodern religion?. En P. Heelas (ed.), Religion, modernity and postmodernity (pp. 55-78). Oxford: Blackwell.

Bauman, Z. (2000). Liquid modernity. Cambridge: Polity Press.

Bauman, Z. (2007). Vida de consumo. Buenos Aires: Fondo de Cultura Económica.

Beck, U. (2001). La reinvención de la política. Hacia una teoría de la modernización reflexiva. En U. Beck, A. Giddens y S. Lash (eds.), Modernización reflexiva. política, tradición y estética en el orden social moderno (pp. 13-73). Madrid: Alianza.

Beck, U., Giddens, A. y Lash, S. (2001). Modernización reflexiva. Política, tradición y estética en el orden social moderno. Madrid: Alianza.

Beck, U. (2009). El Dios personal. La individualización de la religión y el "espíritu" del cosmopolitismo. Barcelona: Paidós. 
Beltrán, W. M. (2005). La diversificación del cristianismo en Bogotá. En A. M. Bidegain y J. M. Demera (eds.), Globalización y diversidad religiosa en Colombia (pp. 257-291). Bogotá: Universidad Nacional de Colombia.

Beltrán, W. M. (2007). De por qué los pentecostalismos no son protestantismos. En C. Tejeiro, F. Sanabria y W. M. Beltrán (eds.), Creer y poder hoy (pp. 469-485). Bogotá: Universidad Nacional de Colombia.

Beltrán, W. M. (2013a). Del monopolio católico a la explosión pentecostal. Pluralización religiosa, secularización y cambio social en Colombia. Bogotá: Universidad Nacional de Colombia.

Beltrán W. M. (2013b). Pluralización religiosa y cambio social en Colombia. Theologica Xaveriana, 63(175), 57-85.

Berger, P. y Luckmann, T. (1997). Modernidad, pluralismo $y$ crisis de sentido. Barcelona: Paidós.

Berger, P. y Luckmann, T. (2003). La construcción social de la realidad. Buenos Aires: Amorrortu.

Bidegain, A. M. (2005). Introducción a la globalización y diversidad religiosa en Colombia. Bogotá: Universidad Nacional de Colombia.

Bidegain, A. M. y Demera, J. D. (2005). Globalización y diversidad religiosa en Colombia. Bogotá: Universidad Nacional de Colombia.

Durkheim, É. (1982). Las formas elementales de la vida religiosa. Madrid: Akal.

Elias, N. (1990). La sociedad de los individuos. Barcelona: Península.

Folquer, C., y Amenta, S. (2010). Sociedad, cristianismo y política. Tejiendo historias locales. San Miguel de Tucumán: Unsta.

Giddens, A. (1997). Modernidad e identidad del yo. Barcelona: Península.
Giddens, A. (2001). Vivir en una sociedad postradicional. En U. Beck, A. Giddens y S. Lash (eds.), Modernización reflexiva. Política, tradición y estética en el orden social moderno (pp. 75-135). Madrid: Alianza.

Guber, R. (2001). La etnografía: Método, campo y reflexividad. Bogotá: Norma.

Hervieu-Léger, D. (2000). Religion as a chain of memory. New Brunswick, N.J.: Rutgers University Press.

Hobsbawm, E. y Ranger, T. O. (1983). The invention of tradition. Cambridge: Cambridge University Press.

Luckmann, T. (1973). La religión invisible. Salamanca: Sígueme.

Luhrmann, T. (2012). A hiperreal God and modern belief: Towards an anthropological theory of mind. Current Anthropology, 53(4), 371-395.

Martin, D. (2002). Pentecostalism: The world their parish. Nueva York: Wiley.

Parker, C. (2005). ¿América Latina ya no es católica? Pluralismo cultural y religioso creciente. América Latina Hoy, 41, 35-56.

Porcentaje de católicos en la región cae 13 puntos en 18 años (27 de abril del 2014). El Tiempo, p. 20.

Riis, O. y Woodhead, L. (2010). A sociology of religious emotion. Oxford: Oxford University Press.

Sarrazin, J. P. y Rincón, L. (2015a). La conversión al islam como estrategia de cambio y diferenciación en la modernidad. Revista de Estudios Sociales, 51, 132-145.

Tejeiro, C., Sanabria F. y Beltrán, W. M. (2007). Creer y poder hoy. Bogotá: Universidad Nacional de Colombia.

Weber, M. (1969). La ética protestante y el espíritu del capitalismo. Barcelona: Península.

Weber, M. (2002). Economía y sociedad. Esbozo de sociología comprensiva. Madrid: Fondo de Cultura Económica.

Para citar este artículo Arango P., y Sarrazin, J. La alternativa cristiana en la modernidad tardía. Razones de la migración religiosa del catolicismo al pentecostalismo. Folios, (46), 41-54. 